\title{
Shear seismic capacity of tuff masonry panels in heritage constructions
}

\author{
G. Marcari ${ }^{1}$, G. Fabbrocino ${ }^{1}$ \& G. Manfredi ${ }^{2}$ \\ ${ }^{1}$ SAVA Department, University of Molise, Termoli, Italy \\ ${ }^{2}$ DIST Department, University of Naples, Naples, Italy
}

\begin{abstract}
Tuff masonry structures have been built since old times in countries located in the Mediterranean areas, and they represent a significant part of the existing masonry building inventory of Central-South Italy, including historical architecture. Due to a lack of knowledge on relevant strength and deformability parameters for tuff masonry, experimental and numerical analyses concerning shear response are certainly of interest. The present paper focuses the attention on single and multiple-leaf tuff masonry walls under different in-plane loading conditions. Experimental displacement-controlled results on large specimens have been used to calibrate finite element (FE) numerical models. A macromodelling approach is used, which is particularly based on a composite plasticity model under plane stress conditions. Comparisons between numerical and experimental results are provided. The ability of the proposed model to fit the overall performances of tuff panels is thus demonstrated. Additional and relevant information about the relation between mechanical parameters of tuff masonry and the corresponding seismic capacity are given for safety assessment and retrofit design purposes.
\end{abstract}

Keywords: masonry, tuff, shear strength, seismic capacity, non linear analysis.

\section{Introduction}

Masonry structures built since ancient times are generally characterised by high levels of seismic vulnerability, thus they generate significant interest especially when development of analysis, assessment and reliable tools for their seismic protection are considered. The problem is complex for all structural types, but is critical for tuff masonry constructions located in Central-Southern Italy regions and particularly in Molise (GNDT [1]). The variety of these buildings, most of 
which were erected according to traditional rules of practice and rarely engineered, requires a rational approach to seismic assessment based on numerical analyses, well supported and validated by experimental tests. In recent years numerical strategies and constitutive models for masonry have been developed for the interpretation of its complex experimental behaviour, but a deeper knowledge of material behaviour is often required via load-displacement controlled tests. In particular, availability of seismic capacity data is crucial for practical applications and safety evaluations issued by modern performance based codes, i.e. US FEMA 356 [2], Eurocode 8 [3] and Italian OPCM 3274 [4]. In addition, validated mechanical parameters and numerical models practiceoriented should be made available on large-scale for practical applications. Therefore, the present work aims at numerical analysis of the monotonic response of typical ancient tuff masonry walls. In particular attention is paid to the response of single and multiple-leaf masonry walls under different in-plane loading conditions. Displacement-controlled experiments on large-scale masonry tests, small masonry sample and basic components (Marcari et al. [5]; Prota et al. [6]; Marcari [7]) provided an extensive database of properties including strength, stiffness characterization and post-peak response, which have been implemented in finite-element analyses. A macro-modelling approach was followed and the composite plasticity model with Rankine type-Hill type yield criteria for plane stress conditions developed by Lourenço et al. [8,9] was adopted.

Comparisons between numerical results and experimental data point out the ability of the proposed model to fit the overall shear performances of tuff panels. Besides, information about correlations between relevant mechanical parameters and seismic capacity of tuff walls is provided.

\section{FEM analysis}

In this section, numerical investigation of the in-plane response of masonry shear-walls were performed via a continuum based approach, which takes into account the anisotropic behaviour of the masonry is briefly reported. DIANA FEM code, ver. 8.1 [10] has been used. The anisotropic composite plasticity model for plane stress structures introduced in Lourenço et al. [8,9], is considered. The model is able to reproduce elastic and inelastic behaviour in two orthogonal directions, the orientation of the bed and head joints of masonry. Two failure mechanisms can be taken into consideration: the first associated to localised tensile fracture processes and the second associated to a more distributed fracture process which can be related to crushing of the material. Orthotropic elasticity is combined with orthotropic plasticity. The model includes the Rankine type-Hill type yield criteria formulated in terms of the stress state components with respect to the material axes. The axes of orthotropy $\mathrm{x}-\mathrm{y}$ are coincident with the material axes, horizontal (bed) joints and vertical (head) joints respectively. The inelastic material parameters of the model are the following: $f_{t x}$ and $f_{t y}$ are the tensile strengths, $G_{f t x}$ and $G_{f t y}$ are the tensile fracture energies, $f_{c x}$ and $f_{c y}$ are the compressive strengths, $G_{f c x}$ and $G_{f c y}$ are the 
compressive fracture energies, $\alpha$ is a parameter depending on the contribution of the shear stress to tensile failure, $\beta$ is a parameter related to the coupling of normal stresses as compressive failure is concerned and $\gamma$ is a parameter which controls the contribution of the shear stress to compressive failure. The fractureenergy based regularization is adopted to mitigate the sensitivity of the results with respect to the mesh size. To this end, an equivalent length $h_{c}$ is incorporated in the model depending on the chosen element type, element size, element shape, integration scheme and even on the particular problem considered. In DIANA $h_{c}$ is related to the area of an element $\mathrm{A}_{\mathrm{e}}\left(h_{c}=\sqrt{2 A_{e}}\right)$; besides for quadratic elements $\alpha_{\mathrm{h}}=1$. In the case of multiple-leaf walls, a regular mesh of 30x30 fournodes quadrilater isoparametric plane stress element, with a $2 \times 2$ Gauss integration scheme was used. The analysis was carried out with the Linear Stiffness iteration method, and the linear stiffness matrix is used all the time. Line search algorithm was used in order to stabilize the convergence behaviour, and it was combined with arc-length method in such a way that snap-through or snap-backs behaviour can be followed. The control of the numerical process took place by means of load control mode. Boundary supports were given at the base of the multiple-leaf panel such that points were fully pinned. Besides, a rigid connection at the top of the wall leads the joints to exhibit the same horizontal displacement. The loading consisted of a vertical load q uniformly distributed along the upper edge of the panel. Self-weight of the panel was considered first. Later on, the horizontal load was applied on the top of the panel. It is worth noting that the main objective of the present study is not the exact reproduction of a single experimental result, but the calibration of relevant mechanical parameters of typical tuff masonry panels so that the overall shear response can be well reproduced. Therefore, ability of the model to fit the experimental results is checked independently on uncertainties related to some numerical parameters associated to anisotropy of masonry. In addition, relevant aspects of the mesh dependency of numerical results are also investigated. It is known, in fact, that numerical analyses of strain softening materials can be mesh dependent even if an energy-based regularization is adopted. Measured elastic and inelastic properties have been used. In particular, the elastic modulus $\mathrm{E}_{\mathrm{y}}$ and the Poisson ratio $v_{\mathrm{xy}}$ were set equal to the experimental values: $\mathrm{E}_{\mathrm{y}}=630 \mathrm{MPa}, v_{\mathrm{xy}}=0.2$; the calibrated shear modulus $G_{x y}=70 \mathrm{MPa}$ was assumed $\left(\mathrm{G}_{\mathrm{xy}}=\mathrm{E}_{\mathrm{y}} / 9\right)$, which resulted close to $\mathrm{E}_{\mathrm{y}} / 6$ suggested by relevant codes. The elastic stiffness $\mathrm{E}_{\mathrm{x}}=600 \mathrm{MPa}$ was lower than $\mathrm{E}_{\mathrm{y}}$, according to literature suggestions (Ganz and Thürlimann [11]). The vertical compressive strength was equal to the experimental value $f_{c y}=1.1$ MPa evaluated onto the gross section area, according to relevant codes. This is a rational approach, even in the present case where a full knowledge of the subassemblage can give additional information. The compressive strength parallel to the bed joints was lower than $\mathrm{f}_{\mathrm{cy}}$, according to technical literature (Hoffmann and Schubert [12]). In particular $f_{c x}$ was set to about $0.5 f_{c y}\left(f_{c x}=0.5 \mathrm{MPa}\right)$. The inelastic behaviour under compression of masonry panels was described by the compressive energy fracture $G_{\mathrm{fc}}$. A mean value of $G_{\text {fcy }}=10 \mathrm{Nmm} / \mathrm{mm}^{2}$ resulted from experimental stress-displacement relationships given in Marcari et al. [5] and Marcari [7]. 
Such a value is in agreement with those calculated from compressive stressstrain relationship reported by references for multiple-leaf tuff panel (Faella et al. $[13,14])$. Since values of $\mathrm{G}_{\mathrm{fcx}}$ were not directly measured, $\mathrm{G}_{\mathrm{fcx}}$ was calibrated and resulted equal to $0.3 \mathrm{G}_{\mathrm{fcy}}\left(\mathrm{G}_{\mathrm{fcx}}=2.7 \mathrm{Nmm} / \mathrm{mm}^{2}\right)$. The masonry tensile strength $\mathrm{f}_{\mathrm{tx}}$ has been then determined as the lowest value corresponding to tension crack in the brick or shear slip along longitudinal joint, after Schubert and Weschke [15]. From available data on tensile strength of mortar samples and stones, and from triplet test results (Prota et al. [6]), the calculated tensile strength was $\mathrm{f}_{\mathrm{tx}}=0.17 \mathrm{MPa}$. The tensile strength $\mathrm{f}_{\mathrm{ty}}=0.06 \mathrm{MPa}$ was set close to the empirical value $f_{t y}=(2 / 3) f_{t, \text { mor }}$ given in Tassios [16], with $f_{t, \text { mor }}$ represents the tensile strength of the mortar. Therefore the following strength ratios were adopted: $f_{c x} / f_{c y}=0.5$; $\mathrm{f}_{\mathrm{tx}} / \mathrm{f}_{\mathrm{ty}}=2.8, \mathrm{f}_{\mathrm{cy}} / \mathrm{f}_{\mathrm{ty}} \approx 18$, on the analogy with similar relations found in masonry technical literature (Pina-Henriques [17]) and $\mathrm{f}_{\mathrm{cx}} / \mathrm{f}_{\mathrm{tx}} \approx 3$. Other inelastic parameters were not available and where assumed to vary within a physical range. In such a way, a calibration of the values for tuff masonry was obtained. Summarize of masonry properties and relevant strength and deformation parameters are given is illustrated in Table 1.

For the numerical analysis of solid walls, a regular mesh of $16 \times 16$ four-nodes quadrilater isoparametric plane stress element, with a $2 \times 2$ Gauss integration scheme was used. The equations related to the finite element discretization were solved using an incremental-iterative Linear Stiffness method, with arc-length control and line search technique.

The simulated loading scheme consisted of vertical compressive force at the upper edge, and of the self weight. Proper boundary conditions at the panel edges were considered in order to simulate the effect of the two steel loading shoes.

Table 1: $\quad$ Summary of masonry parameters for non-linear analysis.

\begin{tabular}{|c|c|c|c|c|}
\hline $\begin{array}{c}\text { Type of } \\
\text { masonry } \\
\text { panel }\end{array}$ & $\begin{array}{c}\text { Elastic } \\
\text { properties }\end{array}$ & $\begin{array}{l}\text { Inelastic properties } \\
\text { Rankine type } \\
\text { Criterion }\end{array}$ & $\begin{array}{l}\text { Inelastic properties } \\
\text { Hill type Criterion }\end{array}$ & $\begin{array}{l}\text { Strength and } \\
\text { deformation } \\
\text { ratios }\end{array}$ \\
\hline $\begin{array}{l}\text { Multiple- } \\
\text { leaf wall } \\
\text { panel }\end{array}$ & $\begin{array}{l}\mathrm{E}_{\mathrm{x}}=600 \mathrm{MPa} \\
\mathrm{E}_{\mathrm{y}}=630 \mathrm{MPa} \\
v_{\mathrm{xy}}=0.2 \\
\mathrm{G}_{\mathrm{xy}}=70 \mathrm{MPa}\end{array}$ & $\begin{array}{l}\mathrm{f}_{\mathrm{tx}}=0.17 \mathrm{MPa} \\
\mathrm{f}_{\mathrm{ty}}=0.06 \mathrm{Mpa} \\
\alpha_{\mathrm{t}}=1.6 \\
\alpha_{\mathrm{h}}=1.0 \\
\mathrm{G}_{\mathrm{ftx}}=0.008 \mathrm{Nmm} / \mathrm{mm}^{2} \\
\mathrm{G}_{\mathrm{fty}}=0.09 \mathrm{Nmm} / \mathrm{mm}^{2}\end{array}$ & $\begin{array}{l}\mathrm{f}_{\mathrm{cx}}=0.5 \mathrm{MPa} \\
\mathrm{f}_{\mathrm{cy}}=1.1 \mathrm{MPa} \\
\gamma=1.2 \\
\beta=-1.5 \\
\mathrm{G}_{\mathrm{fcx}}=2.7 \mathrm{Nmm} / \mathrm{mm}^{2} \\
\mathrm{G}_{\mathrm{fcy}}=10 \mathrm{Nmm} / \mathrm{mm}^{2}\end{array}$ & $\begin{array}{l}\mathrm{E}_{\mathrm{x}} / \mathrm{E}_{\mathrm{y}}=0.95 \\
\mathrm{f}_{\mathrm{cx}} / \mathrm{f}_{\mathrm{cy}}=0.45 \\
\mathrm{f}_{\mathrm{tx}} / \mathrm{f}_{\mathrm{fy}}=2.8 \\
\mathrm{f}_{\mathrm{cy}} / \mathrm{f}_{\mathrm{fy}}=18 \\
\mathrm{f}_{\mathrm{c}} / \mathrm{f}_{\mathrm{tx}}=3 \\
\mathrm{G}_{\mathrm{fcx}} / \mathrm{G}_{\mathrm{fcy}}=0.27 \\
\mathrm{G}_{\mathrm{ftx}} / \mathrm{G}_{\mathrm{fty}}=0.08\end{array}$ \\
\hline Solid wall & $\begin{array}{l}\mathrm{E}_{\mathrm{x}}=647 \mathrm{MPa} \\
\mathrm{E}_{\mathrm{y}}=680 \mathrm{MPa} \\
v_{\mathrm{xy}}=0.15 \\
\mathrm{G}_{\mathrm{xy}}=110 \mathrm{MPa}\end{array}$ & $\begin{array}{l}\mathrm{f}_{\mathrm{tx}}=0.35 \mathrm{MPa} \\
\mathrm{f}_{\mathrm{ty}}=0.12 \mathrm{Mpa} \\
\alpha_{\mathrm{t}}=1.6 \\
\alpha_{\mathrm{h}}=1.0 \\
\mathrm{G}_{\mathrm{ftx}}=0.008 \mathrm{Nmm} / \mathrm{mm}^{2} \\
\mathrm{G}_{\mathrm{fty}}=0.09 \mathrm{Nmm} / \mathrm{mm}^{2}\end{array}$ & $\begin{array}{l}\mathrm{f}_{\mathrm{cx}}=0.69 \mathrm{MPa} \\
\mathrm{f}_{\mathrm{cy}}=2.3 \mathrm{MPa} \\
\gamma=1.2 \\
\beta=-0.6 \\
\mathrm{G}_{\text {fcx }}=1.6 \mathrm{Nmm} / \mathrm{mm}^{2} \\
\mathrm{G}_{\text {fcy }}=6 \mathrm{Nmm} / \mathrm{mm}^{2}\end{array}$ & $\begin{array}{l}\mathrm{E}_{\mathrm{x}} / \mathrm{E}_{\mathrm{y}}=0.95 \\
\mathrm{f}_{\mathrm{cx}} / \mathrm{f}_{\mathrm{cy}}=0.3 \\
\mathrm{f}_{\mathrm{tx}} / \mathrm{f}_{\mathrm{ty}}=2.9 \\
\mathrm{f}_{\mathrm{cy}} / \mathrm{f}_{\mathrm{ty}}=19 \\
\mathrm{f}_{\mathrm{cx}} / \mathrm{f}_{\mathrm{tx}}=2 \\
\mathrm{G}_{\mathrm{fcx}} / \mathrm{G}_{\mathrm{fcy}}=0.27 \\
\mathrm{G}_{\mathrm{ftx}} / \mathrm{G}_{\mathrm{fty}}=0.08\end{array}$ \\
\hline
\end{tabular}

The elastic modulus $\mathrm{E}_{\mathrm{y}}$ and the Poisson ratio $v_{\mathrm{xy}}$ were set equal to the experimental values: $\mathrm{E}_{\mathrm{y}}=680 \mathrm{MPa}, v_{\mathrm{xy}}=0.15$. The shear modulus was set equal to $\mathrm{E}_{\mathrm{y}} / 6=110 \mathrm{MPa}$ (OPCM [4]), while the elastic stiffness in the direction parallel to the bed joints $\mathrm{E}_{\mathrm{x}}$ was equal to $0.95 \mathrm{E}_{\mathrm{y}}=647 \mathrm{MPa}$, on the analogy with FEM 
analysis of multiple-leaf panels. The experimental value of the vertical compressive strength was used, $\mathrm{f}_{\mathrm{cy}}=2.3 \mathrm{MPa}$, wherease the horizontal compressive strength had to be calibrated as $0.30 \mathrm{f}_{\mathrm{cy}}=0.69 \mathrm{MPa}$, so that experimental behaviour could be correctly reproduced. The compressive energy fracture $G_{\text {fcy }}$ of $6 \mathrm{Nmm} / \mathrm{mm}^{2}$ resulted from the integral of the experimental stress-displacement relationship given in Prota et al. [6]. The compressive fracture energy $G_{\text {fcx }}$ was about $0.3 \mathrm{G}_{\mathrm{fcy}}$, according to FEM analysis of multipleleaf panels $\left(\mathrm{G}_{\mathrm{fcx}}=1.6 \mathrm{Nmm} / \mathrm{mm}^{2}\right)$. Due to the lack of available data about uniaxial tensile behaviour, the tensile fracture energies were considered equal to those of the multiple-leaf specimens, assuming, thus, $\mathrm{G}_{\mathrm{ftx}}=0.008 \mathrm{Nmm} / \mathrm{mm}^{2}$ and $\mathrm{G}_{\mathrm{fty}}=0.09 \mathrm{Nmm} / \mathrm{mm}^{2}$. With reference to the strength ratio $\mathrm{f}_{\mathrm{cy}} / \mathrm{f}_{\mathrm{ty}}$ of multiple-leaf panels, the masonry tensile strength $\mathrm{f}_{\mathrm{ty}}$ has been determined according to about $\mathrm{f}_{\mathrm{cy}} / 18\left(\mathrm{f}_{\mathrm{ty}}=0.12 \mathrm{MPa}\right)$. Besides $\mathrm{f}_{\mathrm{tx}} \approx 2.9 \mathrm{f}_{\mathrm{ty}}=0.35 \mathrm{MPa}$. Other inelastic parameters were investigated by a numerical study where each parameter was varied in a physically realistic range, and the ones that best fit the experimental response were selected. Masonry parameters and relevant strength and deformation ratios are given in Table 1. The sensitivity of the numerical responses with respect to the uncertain parameters (difficult to be measured in practice) has been also assessed, but not reported herein for sake of brevity.

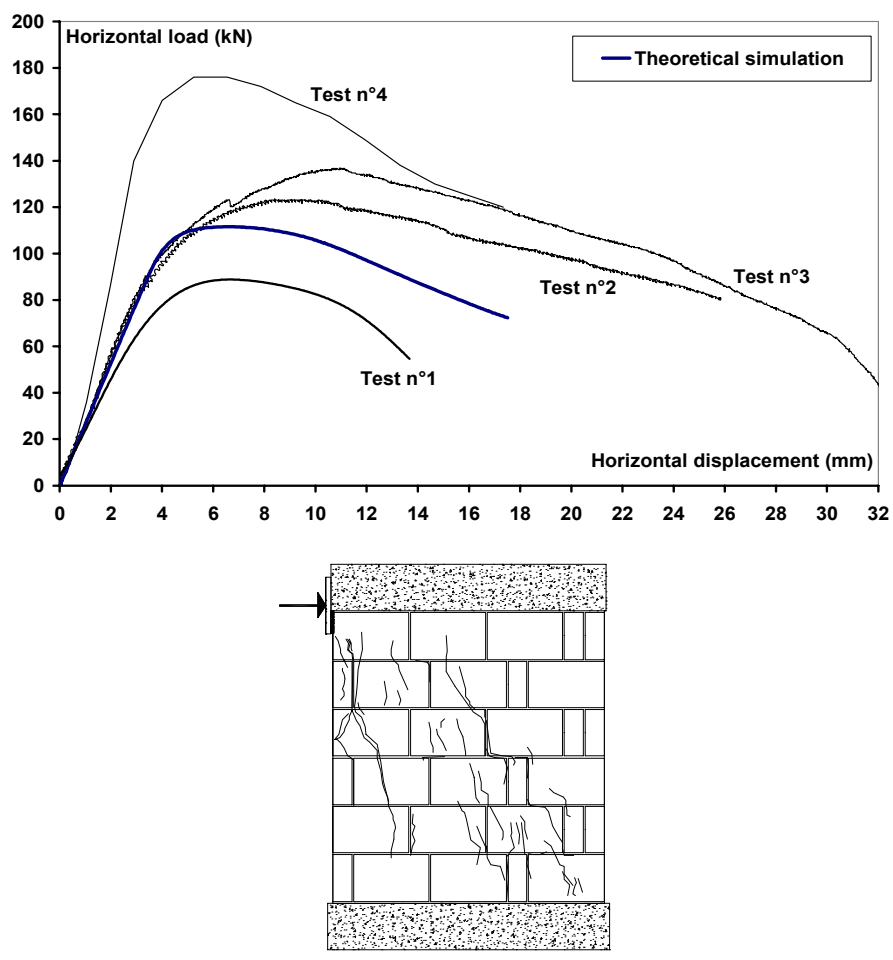

Figure 1: Experimental vs. numerical load-displacement curves and typical crack pattern at failure for multiple-leaf panel. 


\section{Numerical results}

Figure 1 shows the comparison between the experimental load-displacement curves denoted as test $n^{\circ} 1,2,3,4$ and the numerical results. The experimental response is very well reproduced in the elastic branch, until the horizontal displacement $\delta_{\mathrm{x}}$ equals about $4 \mathrm{~mm}$ that basically corresponds to the diagonal shear crack openings of the panels. A good agreement is also found with respect to the collapse load, which results about $15 \%$ lower than the mean experimental value.

An overall good agreement is found even in the post-peak phase. Numerical response of the wall is depicted in Figure 2, in terms of deformed meshes and principal stresses at displacements of 4 and $14 \mathrm{~mm}$, corresponding to $0.25 \%$ and $0.89 \% \mathrm{drift} \delta_{\mathrm{x}} / \mathrm{H}$ ratios, respectively. During the entire loading process, cracks in the panels developed in a large band that goes through the top-left and the bottom right corner. This again agrees with the general trend of experimental results. It was observed that a large reserve of strength was showed, and the concentration of the minimum principal stresses in the shear band, that lead to local crushing of the corners. Therefore, the failure mechanisms observed in the experiments are well captured by the model.
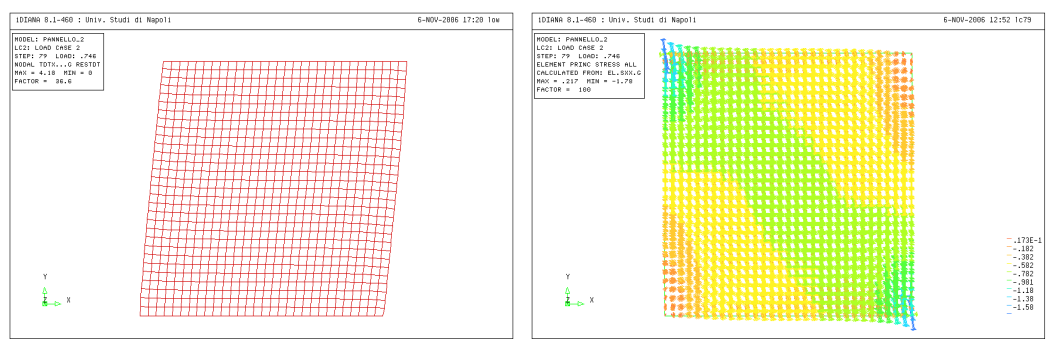

$\delta_{\mathrm{x}}=4 \mathrm{~mm}-\delta_{\mathrm{x}} / \mathrm{H}=0.25 \%$.

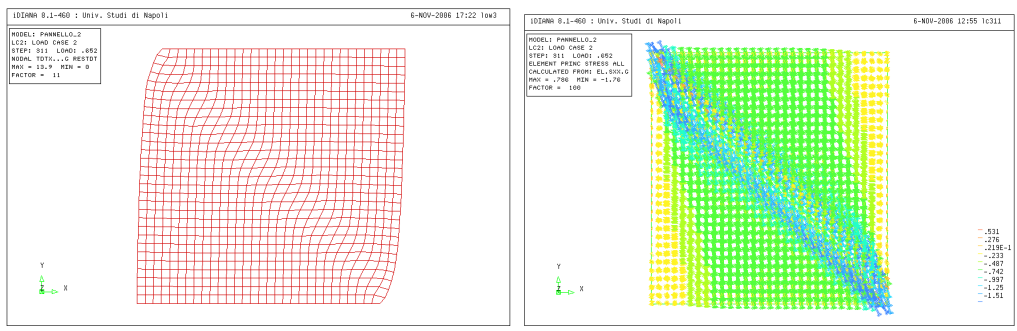

$$
\delta_{\mathrm{x}}=14 \mathrm{~mm}-\delta_{\mathrm{x}} / \mathrm{H}=0.89 \% \text {. }
$$

Figure 2: Deformed mesh and principal directions of stresses at different drifts $\delta \mathrm{x} / \mathrm{H}$. 
Figure 3 shows the comparison between the experimental shear stress vs. vertical deformation and the numerical results of solid wall panels. The experimental curves are denoted as test $n^{\circ} 1,2,3,4$. The predicted shear strength was computed as $\tau=0.707 \mathrm{~V} / \mathrm{A}$, where $\mathrm{V}$ is the applied load and $\mathrm{A}$ the cross section area $\left(\mathrm{A}=0.257 \mathrm{~m}^{2}\right)$, according to ASTM E51981 [19].

Comparing results in terms of initial stiffness, it is possible to observe that the numerical response well reproduce the elastic behaviour, until about $\varepsilon_{\mathrm{v}}=-0.005$ that basically corresponds to the first cracking load. Another important aspect is that a good agreement was achieved in terms of strength, since the numerical peak strength is found only $12 \%$ higher than the mean experimental value.

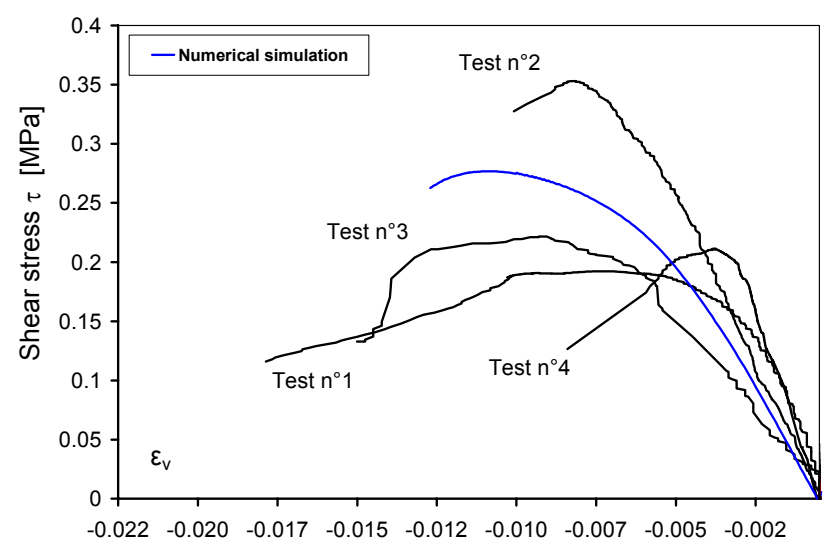

Figure 3: Experimental vs. numerical load-displacement curves and typical crack pattern at failure for solid masonry panel.

Again, the softening behaviour is well captured by numerical analyses on the analogy with results obtained for multi-leaf panels. Behaviour of the solid wall is depicted in Figure 4 in terms of deformed meshes and principal stresses at vertical displacements of $-1.43 \mathrm{~mm}$ and $-4.9 \mathrm{~mm}$, corresponding to the cracking load and the ultimate load, respectively. 

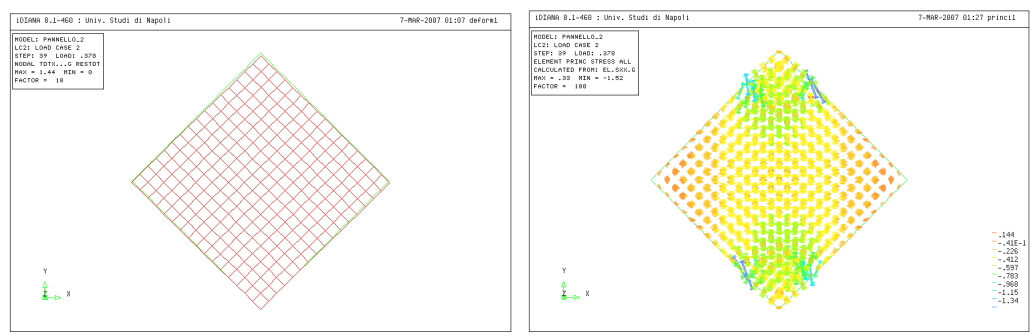

$\delta_{\mathrm{y}}=-1.43 \mathrm{~mm}-$ Cracking Load.
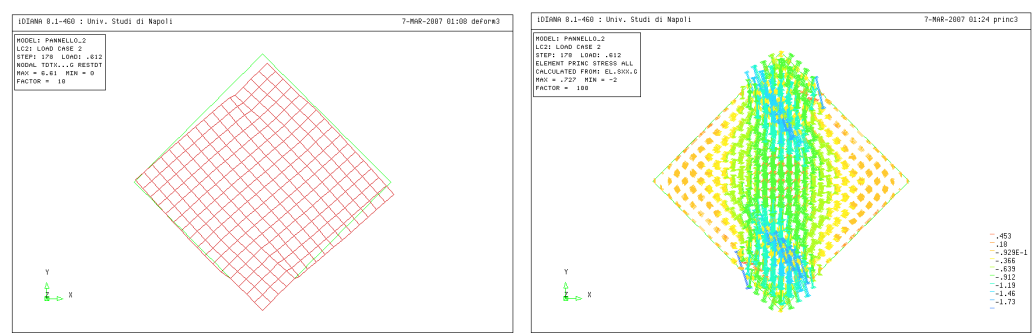

$\delta_{\mathrm{y}}=-4.9 \mathrm{~mm}-$ Ultimate load.

Figure 4: Deformed mesh and principal directions of stresses at different vertical displacement $\delta y$.

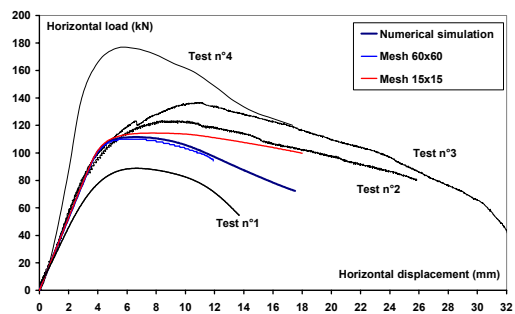

(a)

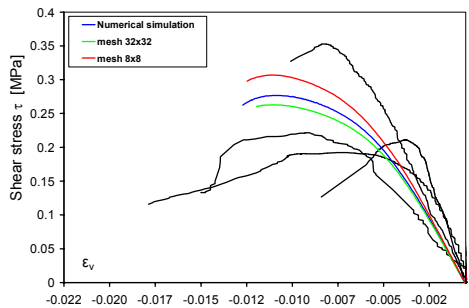

(b)

Figure 5: Mesh sensitivity of the numerical results for multiple-leaf wall (a); solid wall (b).

Crack pattern obtained by macro-modeling mainly arise in a large band that goes through the top and the bottom corner, combined with crushing cracks occurred near the steel loading shoes. The difference found between predicted and observed failure mechanism can be attributed to the approximation of macro-modeling approach which treats masonry as a continuum.

Mesh sensitivity of numerical response is analysed in Figure 5 both for multiple-leaf and solid wall panels. Two meshes sizes were considered, refined by factors 0.5 and 2, respectively. The maximum difference in terms of collapse load is approximately $3 \%$ for multiple-leaf wall, and the maximum difference in 
peak strength is about $11 \%$ for solid wall. Besides the predicted failure mechanism remains the same. In summary predicted results can be considered mesh independent for practical purposes.

\section{Conclusions}

Numerical simulations of the experimental response of two different types of tuff masonry panels subjected to monotonic shear loading have been performed. A refined anisotropic continuum model is adopted and interpretation of results has been carried out using DIANA FEM code, ver. 8.1. It is shown that, if a macromodeling strategy can be applied, the proposed anisotropic model is able to well predict the behaviour of masonry structures, as well as sufficiently accurate postpeak response and failure mechanisms, even some aspects need further optimizations. For non-linear analysis of tuff masonry structures, calibration of relevant parameters is carried out, and correlations between relevant mechanical parameters for both multiple-leaf and solid panels is provided. This is certainly of interest since experimental databases are generally poor and does not lead to fully satisfactory code provisions and retrofit design. Experimental and numerical results can be therefore considered an additional step in the perspective of full knowledge in the behaviour of tuff masonry structures.

\section{References}

[1] Gruppo Nazionale per la Difesa dai Terremoti GNDT, Censimento di vulnerabilità a campione dell'edilizia corrente dei Centri abitati, nelle regioni Abruzzo, Basilicata, Calabria, Campania, Molise, Puglia e Sicilia. Progetto LSU, 2000 (in Italian).

[2] FEMA Prestandard and Commentary for the Seismic Rehabilitation of Buildings, Rep. FEMA 356, Washington, DC, Federal Emergency Management Agency, 2000.

[3] European Committee for Standardization (CEN 2003), Design provisions for earthquake resistance of structures - Part 1: General rules, seismic actions and rules for buildings, EN 1998-1, Eurocode 8, Brussels, Belgium, 2003.

[4] Ordinanza n. 3431. Ulteriori modifiche ed integrazioni all'ordinanza del Presidente del Consiglio dei Ministri. n. 3274 del 20 marzo 2003. OPCM 3431, Gazzetta Ufficiale n.107, 10 maggio 2005 (in Italian).

[5] Marcari, G., Prota, A., Manfredi, G. \& Pecce, M., In-plane shear performance of masonry panels strengthened with FRP. Composites Part $B$ : Engineering, 2007 (article in press).

[6] Prota, A., Marcari, G., Fabbrocino, G., Manfredi, G. \& Aldea, C. Experimental In-Plane Behavior of Tuff Masonry Strengthened with Cementitious Matrix-Grid Composites. ASCE Journal of Composites for Construction, 10(3), pp. 223-233, 2006. 
[7] Marcari, G., Rinforzo sismico di murature di tufo con materiali fibrorinforzati. Tesi di Dottorato di Ricerca in Ingegneria delle Costruzioni, Università degli Studi di Napoli Federico II, Napoli, 2004.

[8] Lourenço, P.B., de Borst R. \& Rots, J.G., A plane stress softening plasticity model for orthotropic materials. Int. Journal for Numerical Methods in Engineering, 40, pp. 4033-4057, 1997.

[9] Lourenço, P.B., Rots, J.G. \& Blaauwendraad, J., Continuum model for masonry: Parameter estimation and validation, ASCE Journal of Structural Engineering, 124(6), pp. 642-652, 1998.

[10] DIANA 2002, Displacement analysis finite element software, version 8.1. TNO-Building Division, Delft, The Netherlands, 2002.

[11] Ganz, H. R., \& Thürlimann, B., Tests on masonry walls under normal and shear loading. Report No. 7502-4, Institute of Structural Engineering, ETH Zurich, Zurich, Switzerland (in German), 1984.

[12] Hoffmann, G. \& Schubert, P. Compressive strength pf masonry parallel to the bed joints. Proc. $10^{\text {th }}$ Int. Brick and Block Masonry Conf, eds N.G. Shrive and A.Huizer, University of Calgary, Calgary, Alberta, Canada, pp.1453-1462, 1994.

[13] Faella, G., Manfredi, G. \& Realfonzo, R., Stress-Strain relationship for Tuff Masonry: Experimental Results and Analytical Formulations. Masonry International, 7(2), pp. 55-61, 1993.

[14] Faella, G., Manfredi, G. \& Realfonso, R., Experimental evaluation of mechanical properties of old tuff masonry subjected to axial loading, Proc. IV Congr. Naz. ASSI.R.C.CO., Prato, Italia, pp.172-179, 1992.

[15] Schubert P. \& Weschke, K., Verformung und Risssicherheit von Mauerwerk, Mauerwerk-Kalender, ed. Ernst \& Sohn, Berlin, Germany, pp. 145-159, 1986.

[16] Tassios, T.P., Meccanica delle murature. Liguori Ed, Napoli, Italia, (in italian), 1998.

[17] Pina-Henriques, J.L., Masonry under Compression: failure analysis and Long-Term Effects. Doctoral Thesis, Escola de Engenharia, Universidade do Minho, October 2005.

[18] European Committee for Standardization (CEN 2005), Design of masonry structures - Part 1-1: General rules for buildings - Rules for reinforced and unreinforced masonry: EN 1996-1-1. Eurocode 6, Brussels, Belgium, 2005.

[19] American Society for Testing Materials (ASTM 1981), Standard test method for diagonal tension (shear) in masonry assemblages. E519-81, Philadelphia, 1981. 